\title{
Concussion Incidence and Time Lost from Play in the NHL During the Past Ten Years
}

\author{
Richard A. Wennberg, Charles H. Tator
}

\begin{abstract}
Background: The problem of concussions in professional hockey has attracted much recent attention. To evaluate the current state of this injury in the National Hockey League (NHL), we analyzed the concussion incidence and time lost from play due to concussions during the past ten NHL seasons. Methods: Data were obtained from a complete review of injury reports in two different sports media sources covering the NHL seasons 1997-98 through 2007-08. Time lost from play was measured in missed games per concussion. Results: The incidence of concussions reported in the regular season ranged from a high of 1.81/1000 athlete exposures in 1998-99 to a low of 1.04/1000 athlete exposures in 2005-06. There was a downward trend in the number of concussions reported per season during the past ten years $(\mathrm{p}=0.01)$. However, average time lost from play per concussion increased over the same period $(\mathrm{p}<0.0005)$. Forwards suffered a disproportionately high percentage of concussions $(\mathrm{p}<0.0001)$. Conclusions: Possibly related to injury reduction efforts, the number of concussions reported per season in the NHL has trended downward in recent years. However, the incidence of concussion remains high and the average time lost from play per concussion has increased. This may reflect increased injury severity in recent years or, alternatively, increased adherence to modern management guidelines preventing premature return to play.
\end{abstract}

RÉSUMÉ: Incidence de la commotion cérébrale et absence du jeu dans la LNH au cours des dix dernières années. Contexte : La commotion cérébrale est un problème qui a retenu l'attention récemment. Nous avons analysé l'incidence de la commotion cérébrale et le temps d'absence du jeu dû à la commotion cérébrale au cours des dix dernières saisons dans la LNH afin de faire le point sur ce type de blessure. Méthodes : Nous avons obtenu les données de revues complètes des rapports de blessures au cours des saisons 1997-98 à 2007-08, publiées par deux sources de couverture médiatique sportive. L'absence du jeu a été mesurée en nombre de parties manquées par commotion cérébrale. Résultats : L'incidence la plus élevée de commotion cérébrale rapportée au cours de la saison régulière était de 1,81/1000 expositions-athlète en 1998-99 et la plus basse de 1,04/1000 expositions-athlète en 2005-06. Nous avons observé une tendance à la baisse dans le nombre de commotions cérébrales rapportées par saison au cours des dix dernières années ( $\mathrm{p}=0,01)$. Cependant l'absence moyenne du jeu par commotion cérébrale a augmenté au cours de la même période ( $\mathrm{p}<0,0005)$. Les joueurs avant ont subi un pourcentage très élevé de commotions cérébrales $(\mathrm{p}<0,0001)$. Conclusions : Nous avons observé une tendance à la baisse du nombre de commotions cérébrales rapporté par saison dans la LNH au cours des dernières années, possiblement due aux efforts déployés en ce sens. Cependant, l'incidence demeure élevée et le temps moyen d'absence du jeu par événement a augmenté, ce qui pourrait s'expliquer par une augmentation de la sévérité des blessures au cours des dernières années ou par un plus grand respect des lignes directrices modernes de traitement empêchant un retour au jeu prématuré.

Can. J. Neurol. Sci. 2008; 35: 647-651

The incidence of concussions in professional hockey has attracted a great deal of media attention, and physicians are occasionally called upon to provide public commentary. ${ }^{1-4}$

In 2003, we showed that the reported concussion rate in the National Hockey League (NHL) during the five seasons from 1997-98 through 2001-02 was more than triple the rate of the previous decade. 5 Based on a sharp increase in reported concussions beginning in 1996-97 and a subsequent plateau in incidence between 1997-98 and 2001-02, the findings were interpreted as representing mainly an increase in diagnostic recognition and reporting after 1997.5

In light of the ongoing public attention and medical commentary surrounding this issue, we have performed an extension of our previous study to document the incidence of concussion and time lost from play in the NHL during the past ten years, comprising the 1997-98 through 2007-08 seasons.

\footnotetext{
From the Divisions of Neurology (RAW) and Neurosurgery (CHT), Krembil Neuroscience Centre, Toronto Western Hospital, University of Toronto, and ThinkFirst, Canada (RAW, CHT), Toronto, Ontario, Canada. Received May 5, 2008. Final Revisions Submitted May 8, 2008. Correspondence to: Richard Wennberg, Toronto Western Hospital, 399 Bathurst St., Suite 5W444, Toronto, Ontario, M5T 2S8, Canada.
} 


\section{Methods}

The NHL concussion program has been collecting data since 1997, but results from this study have not been formally published.,6 Modern media reports of injuries in professional sports provide a means to obtain data that are not otherwise available, and such reports have been documented to be very accurate. $^{7}$

In our previous study, we used injury data obtained from The Hockey News (THN; www.thn.com, Transcontinental Publications, Montreal, QC), which derive from reports submitted to the NHL by individual teams based on information provided by team physicians or certified athletic trainers. ${ }^{5}$ We have used this resource again, reviewing all weekly injury reports for concussions during the ten NHL regular seasons from 1997-98 through 2007-08.

Recently, other investigators ${ }^{8}$ have used NHL injury data obtained from The Sporting News Hockey Register (SNHR; www.sportingnews.com, Sporting News Books, Vulcan Sports Media, St. Louis, MO), published annually over the years covered by this study up to 2006 . This resource provided detailed injury information on all NHL players active during the year of publication. ${ }^{8}$ We reviewed annual editions of SNHR for reported regular season concussions and number of games missed due to each concussion. The position played by each injured player was also noted. The Sporting News Hockey Register was not published after the 2006-07 season: for this season data were obtained directly from STATS (Sports Team Analysis and Tracking Systems) LLC, which had compiled the statistics for SNHR, either directly from the company (2006-07 season) or accessed online through the website of The Sports Network (www.tsn.ca/nhl/injuries; 2007-08 season). Season by season data on the number of penalties and power plays were obtained from the NHL website (www.nhl.com/superstats).
Concussion incidence per season was calculated as follows: Incidence of concussions per 1000 athlete exposures $(\mathrm{AE})=$ (Number of concussions reported during the season / Number of AE during the season) $x$ 1000; where AE during one regular NHL season $=$ Number of players $($ defined as 20 players per team $\mathrm{x}$ number of teams) x Number of games ( 82 per season).

\section{RESULTS}

A summary of the data on numbers of concussions, penalties, power plays, and the average time lost from play per concussion is presented in Table 1. Concussion numbers represent all regular season "concussion" or "head" injuries reported in either or both THN and SNHR/STATS. Eleven percent of the total number of concussions were documented in THN only and $20 \%$ were documented in SNHR/STATS only, which is reflected in higher numbers per season between 1997-98 and 2001-02 than we previously reported. "Head injury" classifications in THN or SNHR/STATS were presumed to represent concussions, and were found to be consistent with such when reviewing other available online media sources describing the same injury. An individual player's "head injury" classification in SNHR/STATS was often a "concussion" classification in THN, or vice versa. Head injuries more specifically described, such as facial lacerations, fractures of facial bones or dental injuries were not considered to represent concussions for the present study. Data for players' time lost from play due to concussions, measured in regular season games missed, were not available for injuries reported only in THN.

Concussion incidence data are presented in Table 2, ranging from a high of 1.81/1000 AE in 1998-99 to a low of 1.04/1000 $\mathrm{AE}$ in 2005-06. Mean incidence over the ten seasons was $1.45 / 1000 \mathrm{AE}$.

Table 1: Concussions, penalties, power plays, and time lost from play, 1997-98 through 2007-08

\begin{tabular}{|c|c|c|c|c|}
\hline Season & Concussions* & Penalties* & Power Plays* & $\begin{array}{l}\text { Median (mean) number games } \\
\text { missed per concussion } \pm \text { standard } \\
\text { deviation }\end{array}$ \\
\hline $97-98$ & 72 & 16,899 & 11,405 & $4(8.6) \pm 15.5$ \\
\hline $98-99$ & 89 & 14,974 & 10,773 & $3(6.9) \pm 11.4$ \\
\hline $99-00$ & 80 & 13,614 & 9,925 & $4(5.7) \pm 6.2$ \\
\hline $00-01$ & 84 & 14,907 & 11,282 & $5(8.8) \pm 13.1$ \\
\hline $01-02$ & 67 & 14,126 & 10,154 & $4(10.4) \pm 16.2$ \\
\hline $02-03$ & 79 & 14,164 & 10,876 & $5(13.3) \pm 18.0$ \\
\hline 03-04 & 70 & 14,144 & 10,427 & $7(14.7) \pm 18.8$ \\
\hline $05-06$ & 51 & 16,913 & 14,390 & $5(10.2) \pm 15.2$ \\
\hline $06-07$ & 58 & 14,515 & 11,935 & $6(13.1) \pm 18.3$ \\
\hline 07-08 & 62 & 13,450 & 10,536 & $6(12.6) \pm 18.3$ \\
\hline
\end{tabular}

*Data from 97-98 through 99-00 adjusted to 30 team equivalents (i.e., raw datum x [30 / number of teams]; 30 teams in NHL from 00-01 through 07-08, 28 teams in 99-00, 27 teams in 98-99, 26 teams in 97-98). No data for 04-05, season cancelled by lockout. 
Table 2: Concussion incidence per season, 1997-98 through 2007-08

\begin{tabular}{cccccc}
\hline Season & Teams & Players & Athlete Exposures (AE) & $\begin{array}{c}\text { Concussions } \\
\text { (raw data) }\end{array}$ & $\begin{array}{c}\text { Incidence } \\
\text { (Concussions } / 1000 \\
\text { AE) }\end{array}$ \\
\hline $97-98$ & 26 & 520 & 42,640 & 62 & 1.45 \\
$98-99$ & 27 & 540 & 44,280 & 80 & 1.81 \\
$99-00$ & 28 & 560 & 45,920 & 75 & 1.63 \\
$00-01$ & 30 & 600 & 49,200 & 84 & 1.71 \\
$01-02$ & 30 & 600 & 49,200 & 67 & 1.36 \\
$02-03$ & 30 & 600 & 49,200 & 79 & 1.61 \\
$03-04$ & 30 & 600 & 49,200 & 70 & 1.42 \\
$05-06$ & 30 & 600 & 49,200 & 51 & 1.04 \\
$06-07$ & 30 & 600 & 49,200 & 58 & 1.18 \\
$07-08$ & 30 & 600 & 49,200 & 62 & 1.26 \\
\hline
\end{tabular}

Figure 1 shows that there has been a downward trend in concussions reported per season during the past ten years, with linear regression analysis of concussions by season demonstrating the downward trend to be significant $(\mathrm{F}=11.20 ; 2$-tailed $\mathrm{p}=0.01)$.

In contrast, Figure 2 shows that there has been a gradual increase in the average number of games missed per concussion during the past ten years. Time lost from play data were available for 310 concussions during the first five seasons of the study period and for 288 concussions during the last five seasons. The mean number of missed games per concussion during the last five seasons was significantly greater than during the first five

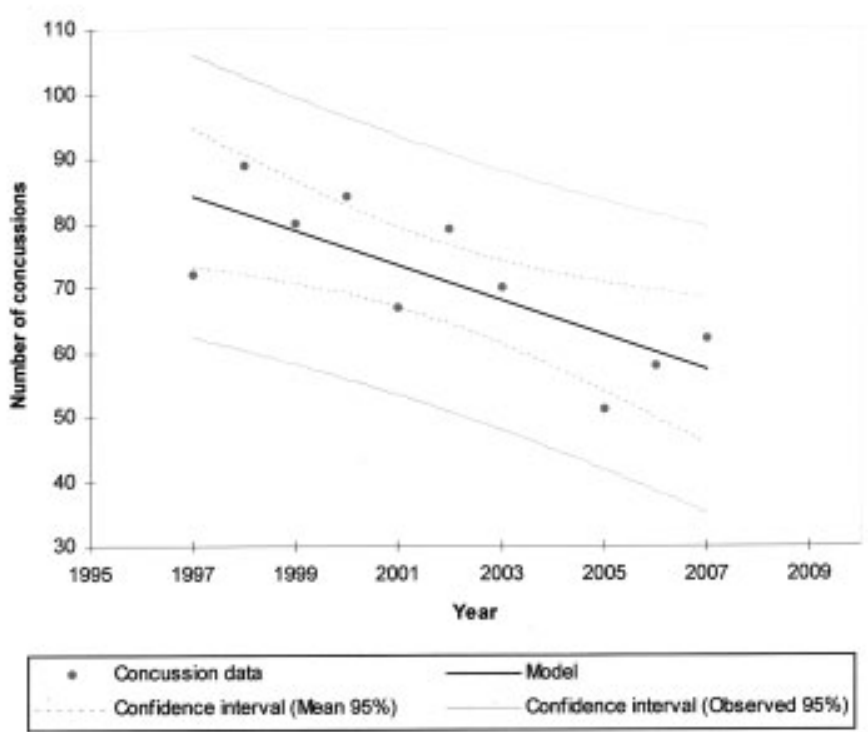

Figure 1: Linear regression of concussions by season $\left(R^{2}=0.583\right)$. seasons $(12.9 \pm 17.8$ vs. $8.3 \pm 13.1$; two sample t-test, unequal variance, $\mathrm{p}<0.0005)$.

To place the data in the context of the biggest change in the game over the study period - the increase in minor penalty calls for "obstruction", interference, holding and hooking upon resumption of play after the 2004-05 NHL lockout - the number of power plays is shown plotted along with the season by season concussion incidence in Figure 2. There was a significant oneyear increase in penalties resulting in power plays during the post-lockout 2005-06 season $(\mathrm{Z}=2.51$; 2-tailed $\mathrm{p}=0.012)$, which was also the season with the lowest incidence of reported concussions (Table 2, Figure 2). The numbers of penalties and power plays in other seasons did not differ significantly from the ten-year means.

With respect to the risk of injury by position played, of the 688 total reported concussions, 428 were incurred by forwards, 241 by defencemen and 19 by goaltenders, indicating a

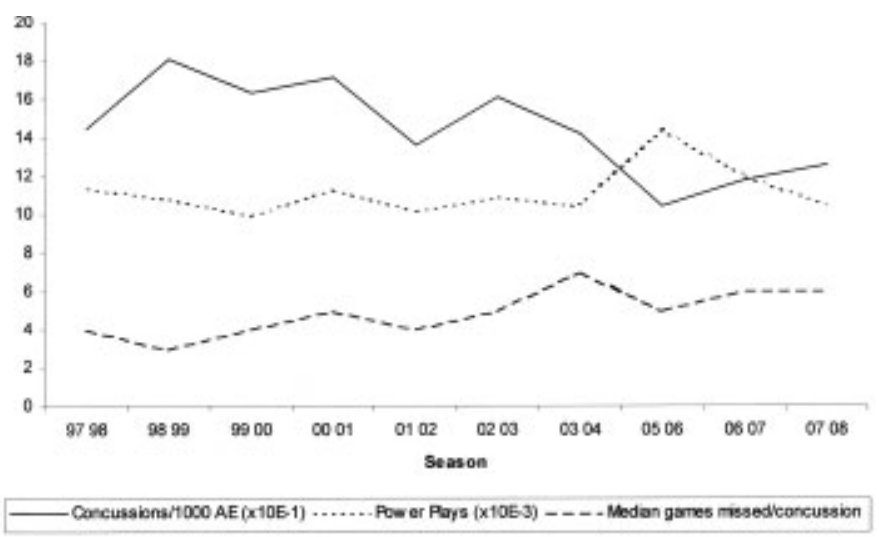

Figure 2: Concussions, power plays and missed games/concussion, 1997-98 to 2007-08. 
significantly higher risk for forwards and lower risk for goaltenders compared with the $3 / 6,2 / 6,1 / 6$ null hypothesis distribution (Chi-square $=101.28, \mathrm{df}=2, \mathrm{p}<0.0001)$.

\section{Discussion}

The NHL itself has accumulated data on incidence, mechanisms of injury and return to play timelines since 1997, 5,6 but has not released these data to the public. An injury analysis panel created by the NHL in 2000 recommended various equipment modifications and strict enforcement of existing rules to reduce deliberate blows to the head. ${ }^{5}$ Possibly related to these latter initiatives, there has been a significant downward trend in concussion incidence in recent years, although the numbers of concussions remain high. Calls from the medical community to institute a complete "no head-checking" rule" have not been heeded by the NHL, although Hockey Canada has established such a rule in all levels of minor hockey, and the major junior Ontario Hockey League followed suit in 2006-07.

Whereas the incidence of reported concussions in the NHL has decreased during the past ten years, there has been a significant increase in the average time lost from play per concussion over the same time period. This could represent either (a) an increased severity of injuries in recent years, or (b) an increased adherence to modern concussion management guidelines, which stress that athletes must not return to play until completely free from all possible concussion-related symptoms. ${ }^{10,11}$ As there are no data available describing injury severity in the NHL, one cannot know which of these two factors is primarily responsible for the increase in games missed per concussion.

Forwards were noted to suffer a disproportionately high (and goaltenders a disproportionately low) percentage of concussions in the NHL, an observation consistent with similar findings in junior and college hockey. ${ }^{12,13}$ One might speculate that a greater amount of time spent carrying or pursuing the puck near the boards, or looking backward while moving forward to receive passes, or crossing the ice in a lateral direction at high speed, amongst other possible risk factors, could be responsible for the increased risk of concussion in forwards. The exact reasons for this increased risk, however, remain to be determined.

During the ten seasons covered in this study, the main structural changes in the NHL game occurred after the 2004-05 lockout, when new rules or enforcement patterns were instituted upon recommencement of play in the 2005-06 season. These changes most notably involved institution of the "no redline" rule for off-side passes and strict enforcement of rules to prevent "obstruction" in all forms. The changes were made in an attempt to "open up" the game and the most dramatic immediate result in the so-called "new NHL" was a significant increase in minor penalties resulting in power plays during the 2005-06 season. This was associated with the largest single season drop in reported concussions during the past ten years. It is possible that this inverse association may not be coincidental, as the nature of hockey played in man-disadvantaged situations is very different from even strength play, with much less body contact in the former setting. ${ }^{3}$ In addition, more space for players to move on the ice (which is the case during power plays) has been shown to be associated with fewer collisions and head impacts in elite hockey. ${ }^{14,15}$ This has led to suggestions that increasing NHL ice surface sizes to international standards or, alternatively, switching to four-on-four hockey, might decrease concussion occurrence..$^{4,14-16}$ It is interesting to note that the downward trend in the incidence of reported concussions during the past ten years may have been due to the decision by the NHL to increase the flow of the game and the scoring of goals by reducing obstruction, rather than as a direct injury prevention strategy. In our view, more needs to be done by the NHL to reduce its devastatingly high rate of concussion.

Over the past decade, at least 20 NHL players have retired because of repeated concussions and many more have been unable to play for extended periods because of post-concussion symptoms. ${ }^{1,5}$ With respect to the overall concussion incidence, it must be acknowledged that the numbers we have reported here are almost certainly an underestimation of the true incidence in the NHL. ${ }^{1,2,5}$ Under-reporting of concussions has been identified at all levels of hockey and attributed to a variety of factors, including a desire on the part of either players or teams to hide injuries ${ }^{5,17}$ However, the ability of an NHL team to hide from the public that a player has missed games due to a concussion in this age of media saturation must be considered very limited. The data from THN and SNHR/STATS documented only concussions resulting in missed games, and as such concussions without time lost from play were not represented. Notwithstanding, it is interesting to note that the mean calculated NHL concussion incidence during the past ten years of 1.45/1000 AE is very similar to the incidence of $1.47 / 1000 \mathrm{AE}$ found using more sensitive injury detection methods in a recently reported study of mens' hockey in the National Collegiate Athletic Association. ${ }^{13}$ And though an underestimation of the true incidence of concussion, the reliability of the NHL data in the present study, which identified only injuries that resulted in missed games, is likely very high. Importantly, it has been convincingly argued that the use of a "game time loss" injury definition is the most accurate and reliable tool for comparing injury rates between different seasons in team sports, as done in this study. ${ }^{18,19}$ It is hoped that the data presented here will prove useful in guiding future discussions on concussions in professional hockey.

In the interest of enhancing the safety of hockey, the NHL should be encouraged to make public the information on concussions that it has collected. For example, it would be very helpful to compare their data with ours to help determine the validity of the data collection methods and to further evaluate the favorable trend we have reported.

\section{ACKNOWLEDGMENTS}

The authors thank Sam McCaig and The Hockey News for kindly allowing us to review their archives for this study. Data obtained for the 2006-07 season directly from STATS LLC, copyright 2007, used under licensed agreement.

\section{REFERENCES}

1. Starkman R. Hockey concussions take a toll. The Toronto Star. 2007 Dec 23; S:1.

2. Reid SM. NHL watches as concussions rise. The Orange County Register. 2007 Sept 23; News:1.

3. Mendoza M. Reducing concussions in the NHL. The Columbian. 2006 Dec 06;B:1. 
4. Wennberg R. Treat hockey injuries with more ice. The Globe and Mail. 2004 Aug 26;A: 17.

5. Wennberg RA, Tator $\mathrm{CH}$. National Hockey League reported concussions, 1986-87 to 2001-02. Can J Neurol Sci. 2003;30: 206-9.

6. Meeuwisse W, Burke C. NHL concussion program. Br J Sports Med. 2001;35:375 (abstract).

7. Orchard J. Who owns the information? $\mathrm{Br} \mathrm{J}$ Sports Med. 2002;36:16-8.

8. Stevens ST, Lassonde M, de Beaumont L, Keenan JP. The effect of visors on head and facial injury in National Hockey League players. J Sci Med Sport. 2006;9:238-42.

9. Pashby T, Carson J, Ordogh D, Johnston KM, Tator CH, Mueller FO. Eliminate head-checking in ice hockey. Clin J Sport Med. 2001;211-3.

10. McCrory P, Johnston K, Meeuwisse W, Aubry M, Cantu R, Dvorak $\mathrm{J}$, et al. Summary and agreement statement of the 2nd international conference on concussion in sport, Prague 2004. Clin J Sport Med. 2005;15:48-55.

11. Carson J, Tator C, Johnston K, Kissick J, Purcell L, Hunt B. New guidelines for concussion management. Can Fam Physician. 2006;52:756-7.

12. Goodman D, Gaetz M, Meichenbaum D. Concussions in hockey: there is cause for concern. Med Sci Sports Exerc. 2001;33: 2004-9.
13. Agel J, Dompier TP, Dick R, Marshall SW. Descriptive epidemiology of collegiate men's ice hockey injuries: National Collegiate Athletic Association injury surveillance system, 19881989 through 2003-2004. J Athl Train. 2007;42:241-8.

14. Wennberg R. Collision frequency in elite hockey on North American versus international size rinks. Can J Neurol Sci. 2004;31:373-7.

15. Wennberg R. Effect of ice surface size on collision rates and head impacts at the World Junior Hockey Championships, 2002 to 2004. Clin J Sport Med. 2005;15:67-72.

16. Moore M. Saving the game. Toronto: McClelland and Stewart; 2006.

17. Williamson IJ, Goodman D. Converging evidence for the underreporting of concussions in youth ice hockey. Br J Sports Med. 2006;40:128-32.

18. Hodgson L, Gissane C, Gabbett TJ, King DA. For debate: consensus injury definitions in team sports should focus on encompassing all injuries. Clin J Sport Med. 2007;17:188-91.

19. Orchard J, Hoskins W. For debate: consensus injury definitions in team sports should focus on missed playing time. Clin J Sport Med. 2007;17:192-6. 